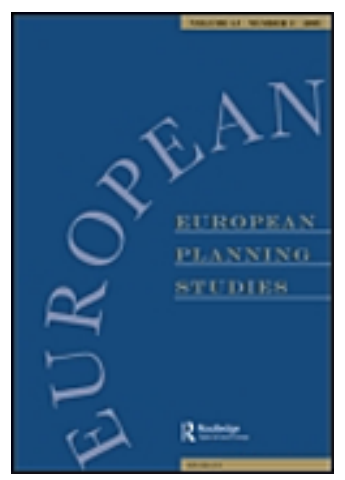

\title{
Start-Up Factories, Transnational Entrepreneurs and Entrepreneurial Ecosystems: Unpacking the Lure of Start-Up Accelerator Programmes
}

\begin{tabular}{|r|l|}
\hline Journal: & European Planning Studies \\
\hline Manuscript ID & CEPS-2018-0179.R1 \\
\hline Manuscript Type: & Original Paper \\
\hline Keywords: & $\begin{array}{l}\text { Transnational Entrepreneurs, Entrepreneurial Ecosystems, Accelerators, } \\
\text { Silicon Valley, Networks }\end{array}$ \\
\hline \multicolumn{2}{|l}{} \\
\hline
\end{tabular}

\section{SCHOLARONE \\ Manuscripts}




\title{
"Start-Up Factories, Transnational Entrepreneurs and Entrepreneurial Ecosystems: Unpacking the Lure of Start-Up Accelerator Programmes"
}

\author{
Ross Brown, University of St Andrews \\ Suzanne Mawson, University of Stirling \\ Neil Lee, London School of Economics \\ Lauren Peterson, University of St Andrews
}




\begin{abstract}
This paper examines the role of accelerator programmes in promoting transnational entrepreneurship. Designed to assist the growth of start-ups by providing seed finance and structured entrepreneurship support, these programmes are now a prominent feature in many entrepreneurial ecosystems around the world. Drawing on in-depth qualitative evidence focused on one particular programme, the paper shows accelerators play an important intermediary or "brokerage mechanism" providing start-ups with enhanced relational connections and networks. Transnational entrepreneurs attracted to these programmes are highly focused on exploiting these networks whilst maintaining multiple levels of embeddedness in various contexts to maximise the opportunities afforded by accelerators. While many governments are attempting to replicate accelerators programmes within the public sector, the paper concludes that such attempts may prove problematic within weaker entrepreneurial ecosystems.
\end{abstract}

Accelerators

Networks
Transnational Entrepreneurs

Public Policy
Entrepreneurial Ecosystems 


\section{Introduction}

This paper examines the role start-up accelerator programmes play in promoting transnational entrepreneurship. Originating in the US, these so-called "start-up factories" (Miller and Bound, 2011) have become commonplace across many entrepreneurial ecosystems (Hochberg, 2016; Brown and Mason, 2017). Designed to grow start-ups by providing seed capital, investment opportunities and structured entrepreneurship education and support, they are now a ubiquitous feature across many European (Pauwels et al, 2016), Asian-Pacific (Bliemel et al, 2018; Seet et al, 208), African (Ganamotse et al, 2017) and emerging market economies (GonzalezUribe and Leatherbee, 2017; Goswami et al, 2018). Some claim there are more than 3000 accelerators worldwide (Hochberg, 2016) and the UK alone has an estimated 163 in operation (Bone et al, 2017). Yet, despite their rapid growth and prodigious ability to nature growthoriented start-ups, accelerators have been subject to limited academic scrutiny (Hathaway, 2016; Clayton et al, 2018). ${ }^{1}$

Early accelerator programmes such as Y Combinator, 500 Start-Ups and RocketSpace typically adopted a private sector equity-funding model (Kim and Wagman, 2014). Under this model, start-ups receive seed funding and a range of structured entrepreneurship support services and mentoring in exchange for a small amount of equity. There are now numerous types of accelerators, with one model being publicly-funded accelerators (Bone et al, 2017). This model is increasingly deployed by the public sector in many European countries to cultivate their local entrepreneurial ecosystems (Hathaway, 2016; Bliemel et al, 2018). In UK peripheral regions such as the North-East, Northern Ireland, Scotland and Wales, around a third of accelerators rely on public funding (Bone et al, 2017). A similar case exists in Finland, where public funding underpins the VIGO accelerator programme operated by TEKES (Business Finland, 2017). These examples of public financial investments are evidence that policy makers view accelerators as "critical" for fostering indigenous entrepreneurial ecosystems (Hochberg, 2016; Bliemel et al, 2018). Indeed,

\footnotetext{
${ }^{1}$ Accelerators such as Y Combinator has been labelled by some as "perhaps the world's most successful entrepreneurial initiative" (Huggins et al, 2018, p. 1302).
} 
in certain respects, accelerators appear to be replacing incubators as the latest "fad" within entrepreneurship policy making, particularly in Europe. ${ }^{2}$

Often a core rationale for the public sector establishing these accelerator programmes is to attract transnational entrepreneurs (henceforth TEs) from other countries to overcome a shortfall of local entrepreneurial "talent". Indeed, this is a core objective for state-funded accelerators such as Chile's Start-Up accelerator programme, which recruits almost $80 \%$ of its start-ups from overseas (Gonzalez-Uribe and Leatherbee, 2017). TEs are defined as people "who migrate from one country to another, concurrently maintaining business-related linkages with their countries of origin and current adopted countries and communities" (Drori et al, 2009, p. 1001). The ability to span multiple national contexts is often a pre-requisite for generating and sustaining their entrepreneurial activities (Yeung 2002; Drori et al. 2009; Terjesen and Elam, 2009), so that these entrepreneurs capitalise on global markets by "leveraging their transnational experience" (Liu, 2017, p. 48).

Owing to the fact that accelerators accept applicants from anywhere in the world, they act as an important intermediary or "brokerage mechanism" between promising entrepreneurs/ventures in far-flung places and local investors (Shane, 2016). Despite this global brokerage process, few studies have sought to explore the role that institutions such as accelerators play in promoting the migration process of TEs to different spatial locations. Indeed, we currently know very little about what motivates TEs to migrate to join accelerators and what role these institutions play in the fostering entrepreneurial migration to different entrepreneurial ecosystems. This issue is critically important given that policy makers have certain conceptions about the ability of accelerators to lure transnational entrepreneurs. Therefore, this paper seeks to address the following broad research question: what is the role played by accelerators in mediating the process of transnational entrepreneurship?

\footnotetext{
${ }^{2}$ There are strong parallels between the adoption of accelerators and business incubators which also originated in the private sector in the US but spread widely sector across Europe in the public sector (Smith and Zhang, 2012).
} 
An in-depth case study methodology was adopted to explore the above research question. The empirical focus of the paper is one particular accelerator programme based in Silicon Valley. We use this specific example to explore the wider phenomenon of how accelerators promote and shape transnational entrepreneurship more widely. We do of course recognise that Silicon Valley is a unique context, especially due to its reputation as a "hot spot" of entrepreneurial activity. Indeed, it was home to approximately 183 accelerators in 2015 (F6S 2015) and has consistently strong rates of high-tech immigrant entrepreneurship (Hart and Acs 2011). That said, valuable lessons can be extracted for accelerators operating elsewhere, especially European countries that have widely adopted the accelerator concept (Pauwels et al 2016).

This paper makes an important contribution to the burgeoning literature on start-up accelerators and transnational entrepreneurship. It finds that the critical motivator for TEs to join an accelerator programme is the desire to augment their relational connections, particularly the desire to work intimately with other dynamic, like-minded entrepreneurs. From an entrepreneurial ecosystems perspective, accelerators appear play a central role in shaping entrepreneurial activity and are undoubtedly acting as powerful drivers (and enablers) of transnational entrepreneurship. Importantly, from a policy transfer perspective, the paper suggests that crude attempts to replicate such accelerators within the public sector (or specific locations) may be problematic.

The remainder of the paper is as follows. First, it examines the relevant academic literature. Second, the methodology deployed is highlighted, before we examine the empirical findings. In the penultimate section we discuss the findings and then offer conclusions and specific areas for further research.

\section{Literature Review}

\subsection{The Nature and Dynamics of Start-Up Accelerators}

Accelerators are an important addition to the types of "specialist infrastructure" available in some entrepreneurial ecosystems (Brown and Mason, 2017). Given that institutions are 
recognised as central actors in fostering entrepreneurship (Rodríguez-Pose 2013; Stam, 2015), interest in how accelerators nurture entrepreneurship has escalated markedly. Indeed, a number of scholars have hinted that accelerators can be an important catalyst for start-ups within different entrepreneurial ecosystems (Bliemel et al, 2018).

Although accelerators are increasingly seen as a crucial new institutional actor, there is currently no concrete definition of this organisational model. This is perhaps unsurprising given the pervasive heterogeneity exhibited across accelerators (Hochberg, 2016) ${ }^{3}$. To date there has been some degree of ambiguity as to what accelerators actually do and how they differ from other related institutions such as incubators (Pauwels et al, 2016). Accelerators mark a departure from traditional business incubation models (Grimaldi and Grandi, 2005; Aerts et al, 2007; Bergek and Norman, 2008), which are typically "property-based initiatives providing their tenants with a mix of value-added services" (Lamine et al, 2018, p. 1123). Accelerators, on the other hand, "hothouse" growth-oriented ventures via seed funding, coaching and peer-based mentoring (Pauwels, 2016).

One of the main differences between incubators and accelerators is their divergent target market and widely varying selection criteria (Hochberg, 2016). Accelerators are typically tailored to wellestablished and later stage start-ups, whereas incubators are focused on very early stage business ideas. Therefore, accelerators seek to provide help to scale-up a fledgling business, rather than to launch ventures. Whilst heterogeneous in nature (Bliemel et al, 2018), the general purpose of accelerators is to stimulate start-up activity by providing seed capital, help identify investment opportunities from local investors and match start-ups with potential customers (Hathaway, 2016; Goswami et al, 2018). A common (and important) trait of most accelerator programmes is the fact that they are cohort-based and time-bound, often lasting for a period of between three to six months. ${ }^{4}$

\footnotetext{
${ }^{3}$ While many are independently-owned, nearly half of all UK accelerator programmes are funded by corporate organisations such as the Barclays UK Fintech Accelerator (Bone et al, 2017).

4 Typically, accelerators recruit start-ups twice a year and conclude with a "demo day" to enable the start-up to "pitch" to an invited audience of potential investors.
} 
Most of the early accelerators in the US provided start-ups with seed finance in return for equity (Kim and Wagman, 2014). ${ }^{5}$ As this provision of seed funding is a common feature of accelerators, it makes them more akin "to business angels than real-estate-based incubators" (Bliemel et al, 2018, p.4). Indeed accelerator funders are similar to equity investors, as they only expect to receive large returns from a minority of ventures (Clayton et al, 2018). Furthermore, the competitive selection process of recruitment into accelerators acts as a signaling effect to outside investors (Kim and Wagman, 2014). Whilst many accelerators obtain revenue from equity stakes in firms, as noted previously an increasing number are now operated by the public sector who generally do not take equity stakes in start-ups (Bone et al, 2017).

Due to a lack of academic work (Clayton et al, 2018), there has been insufficient consideration given to the precise nature of the role played by accelerators as intermediary organisations. Initial research suggests that their primary role is their ability to provide start-ups with sources of capital, advice and intensive support through peer-based mentoring (Hathaway 2016). These types of transactional services are found in nearly all accelerators across a variety of spatial contexts (Bliemel et al, 2018; Goswami et al, 2018). However, most studies examining accelerators find that many start-ups obtain important relational benefits from being involved in these programmes (Seet et al, 2018). Recent empirical examination of accelerators has shown that a key perceived benefit from participation in an accelerator programme is the relational and social capital it confers upon accelerator participants (Seet et al, 2018; Goswami et al, 2018).

Researchers have also highlighted the important intermediary role these organisations play in connecting entrepreneurial ventures with potential sources of funding, new customers and peerbased mentors (Kohler, 2016; Hathaway, 2016; Shane, 2016). While the role of intermediaries has been closely examined within the innovation systems literature (Howells, 2006), there has been less attention paid to this principle within the entrepreneurship sphere (Dutt et al, 2016).

\footnotetext{
${ }^{5}$ Under this model, accelerators take a small stake in the ventures (between $5-7 \%$ ) in return for a small equity stake in the firm (Hochberg, 2016). For example, Y Combinator takes an average of 6\% equity in each start-up in return for $\$ 11,000$ seed funding.
} 
This is surprising because intermediaries such as accelerators potentially play a very powerful role in the entrepreneurship process in terms of alleviating information asymmetries facing small firms, such as difficulties obtaining finance from investors (Cassar, 2004). These types of intermediary roles enable accelerators to act as "middlemen" or "network intermediaries", connecting firms with access to sources of finance, contacts and expertise (Howells, 2006).

Scholars maintain that there is an urgent need to better understand how particular institutions mediate and promote cross-border entrepreneurship (Yeung 2002; Liu, 2017). Intermediaries such as accelerators can often overcome liabilities of distance confronting entrepreneurs. Shane (2016), for example, notes how accelerators help to overcome geographical difficulties facing entrepreneurs by acting as "brokerage mechanisms" between promising entrepreneurs/ventures in far-flung places and local investors. This is particularly important for start-ups, as a lack of capital "causes many start-ups to look overseas for venture capital" (Bliemel et al, 2018, p. 13).

\subsection{Transnational Entrepreneurship}

The literature on TEs remains relatively sparse (Portes et al, 2002; Yeung 2002) despite dating back almost 20 years. However, there is now an emerging body of work on the determinants of transnational entrepreneurship (Yeung, 2002; Drori et al, 2009; Terjesen and Elam, 2009; Dimitratos et al, 2016; Pruthi et al, 2018). From a theoretical perspective, resource dependency theory is often deployed (Pfeffer and Salancik 2003) to explain why entrepreneurs seek to take advantage of resources unavailable in their home context, such as venture capital and wider networks, to mitigate resource deficiencies at home (Ferrary and Granovetter 2009). One of the first studies to empirically examine this growing phenomenon was Saxenian's (2006) pioneering work in Silicon Valley. Saxenian (2006) noted how Indian and Chinese TEs accounted for three in ten of Silicon Valley's high-performance start-ups. Because of their experience and multinational professional networks, these dynamic entrepreneurs quickly identified promising new market opportunities, raised capital, built management teams and established partnerships with other specialist producers often located far away (Saxenian, 2006). 
While we know that these entrepreneurs play an important role in the development of dynamic agglomerations (Saxenian 2002, 2006), we still understand very little about what motivates entrepreneurs to relocate to particular environments and how the complex interplay of local, regional and institutional factors mediate these migratory processes. In particular, scholars maintain there is a need to better understand how institutional differences shape the way in which TEs operate (Yeung, 2002). Within this perspective, the strategies formed by TEs are considered to be inherently shaped by the social and institutional factors, both in their home and adopted environments, where entrepreneurs can gain "significant international business knowledge and experience form his/her enrolment into actor networks elsewhere" (Yeung 2002, p. 52) as well as access to required resources (Drori et al. 2009). Once embedded in these institutional structures and networks, TEs can "make use of their entrepreneurial endowments and resources" (Yeung 2002, p. 53) to enhance their new ventures and other international business activities. While the importance of networks is often highlighted in the literature, studies often fail to demonstrate "how and under what circumstances networks matter" (Chen and Tan 2009, p. 1080).

Whilst previous literature helps inform our thinking on the key determinants behind transnational entrepreneurship, critically it neglects the individual motivations entrepreneurs have for migrating to particular entrepreneurial ecosystems. As TEs "take exceptional risks and initiatives to overcome immense difficulties of operating and managing in foreign business systems" (Yeung 2002, p. 54), there is arguably a need for a greater focus on individual personal motivations or "agency" when exploring this population of entrepreneurs. In terms of setting out a future research agenda on TEs, scholars claim more needs to be known about how they "actively engage and develop business activities in an actual business environment" (Driori et al, 2009, p. 1016). Whilst access to resources may be one driver, there are undoubtedly other relational, financial and institutional aspects of specific entrepreneurial ecosystems that promote migration and transient relocation. This paper seeks to examine empirically the specific role 
played by accelerators as new entrepreneurial actors in mediating the process of transnational entrepreneurship.

\section{Method}

This study adopted a case study method. This is considered to be a suitable methodological approach where theory remains nascent and underdeveloped (Eisenhardt, 1989), as is the case with accelerators and transnational entrepreneurship. The main unit of analysis within this study is an accelerator based in Silicon Valley, which is used to explore the wider phenomenon of how accelerators shape transnational entrepreneurship. The research focused on one particular accelerator programme that agreed to cooperate in this study. This programme was selected as it represented one of a growing breed of innovative and fast-moving accelerators to originate in Silicon Valley. The chosen accelerator also had strong interest from overseas TEs. A key element of the construction of the accelerator case study comprised in-depth narrative interviews with TEs applying to join this accelerator programme. Given that accelerators are highly secretive and acutely protective of proprietary and/or client-related information, at their request, the names of the programme and the entrepreneurs interviewed were withheld.

To identify interview participants, a sample of 20 accelerator applicants were identified by the accelerator's management team from a total applicant pool of 185 entrepreneurs who applied at the point at which sampling took place. While a strict purposive or theoretical sampling (Eisenhardt, 1989) approach was not possible owing to the fact that the researchers were not able to pre-select the entrepreneurs to interview, care was taken that the cohort identified corresponded to the transnational entrepreneur phenomenon identified within the literature. Therefore, all the interviewees wished to migrate to develop their new venture and all had preexisting ties in their home and/or other alternative entrepreneurial ecosystems.

Given the focus of the research, the sample was international in origin and was representative of the larger applicant pool. Of the 20 applicants the researchers were authorised to approach, eight agreed to participate in the research. All of these entrepreneurs were located outside the 
US when the interviews took place. Two interviews with the founding owners of the accelerator were also undertaken to triangulate the eight cases, as well as to explore observations of the wider cohort of accelerator applicants. An additional interview was conducted with one firm that had received assistance through a different accelerator programme but had subsequently exited. This was used to triangulate the experiences of the TEs on the appeal of accelerators and how accelerators work in practice.

Narrative or 'conversational' interviews were conducted in English via videoconference software and were digitally recorded and transcribed immediately upon completion. During the interviews, which were between 1 and 1.5 hours in length, particular attention was paid to personal drivers and motivations for relocation in the context of the entrepreneurs' own personal narratives, although questioning was avoided during the main narration. Linked to our core research question, the primary emphasis within the interviews was the specific rationale for wishing to join the accelerator programme. However, the interviewees were also asked about the nature of their domestic entrepreneurial ecosystem to see how this linked to the migratory behaviour and nature of resource assembly within the entrepreneurs' examined.

The interview material and subsequent written material was interpreted using the constant comparative method; a partially 'grounded' approach in which the data was systematically analysed to tease out themes, patterns and categories (Easterby-Smith et al. 2002). It was partially grounded in that some of the issues within the study emerged inductively from the data through a process of "concept discovery" (Martin and Turner, 1986), for example the perceived importance attributed to relational connections. Other issues arose through explicit probing around relevant themes from the literature (i.e. desire for resources). The data was coded in three iterative phases (open, axial and selective/theoretical) as initially presented by Strauss and Corbin (1998). When key categories/sub-categories emerged, they were refined and reevaluated by each of the researchers. The data collected was also subjected to 'within-case' and 'cross-case' analysis to tease out additional commonalities and differences. A number of core themes emerged from the coding process, specifically the cognitive mindset of TEs, the perceived 
benefits of Silicon Valley and the link to their "home" entrepreneurial ecosystems. These will be discussed in detail in section 4.

\subsection{Profile of the Accelerator Programme and Applicants}

Participation onto this selected accelerator programme is competitive and occurs in batches or cohorts when the group of selected start-ups commence at the same time. The programme offers accommodation, seed funding and mentoring in return for a small equity stake in the firm. As with most accelerator programmes in Silicon Valley, the start-ups are offered intensive mentoring, introductions to larger corporate companies and contacts with local investors.

Approximately three quarters of the total applications to join the accelerator programme $(n=185)$ came from entrepreneurs located outside of the US. The largest sources of foreign applicants came from English speaking countries such as India, the UK and Canada. These countries comprised approximately one fifth of all applicants, with India being the single largest source of applicants after the US. What was most noticeable about this cohort of applicants was the vast level of geographical diversity. While the majority came from developed or emerging markets (such as Brazil, India and China), a number of applications also came from developing economies such as Vietnam, Indonesia, etc. The vast majority of applicants to the accelerator were technology entrepreneurs, running software-based firms covering areas such as internet, social and mobile including 'app' based firms. E-commerce, finance/payments and IT services were also prevalent, as reflected in our interviewees (see Table 1 below).

\subsection{Demographic Profile of Entrepreneurs}

Detailed demographic information about the TEs interviewed is outlined below in Table 1. Our respondents closely matched the nature of the overall cohort of applicants. The eight entrepreneurs interviewed were all relatively young, in their late 20s to mid-30s, with an average age of 32. All the entrepreneurs were male, which was in line with the male-dominated profile of the overall population of applicants to the programme (close to $80 \%$ ). The entrepreneurs were from a wide variety of different countries including Australia, Belgium, Brazil, Dominican 
Republic, India, Italy, Mexico and Poland. Nearly all the TEs interviewed were currently located in major urban locations such as Dublin, London, Mexico City and Sydney.

Corresponding with the overall cohort of applicants, each of our entrepreneurs had intellectual property (IP) (software or IT-related technologies) they wished to develop in the context of the accelerator. The majority were highly skilled and all had undertaken university-level higher education, predominantly with science or business degree qualifications. The interviewees were a highly ambitious cohort corresponding with stereotypical growth-oriented entrepreneurs, who desire to create wealth and growth through innovative ideas and practices.

\section{[Insert Table 1 about here]}

In terms of their entrepreneurial experience, half of the entrepreneurs had prior experience of starting a business and the other half were de novo starts. Relatedly, some had quite considerable experience, such as entrepreneur $F$ who had over 15 years of running various ventures in Mexico. In three other cases, entrepreneurs D, E and G all had quite considerable entrepreneurial experience. Plus, one of the de novo entrepreneurs from India had pre-existing experience of working within his family-owned business (entrepreneur $\mathrm{H}$ ). Consequently, many of these entrepreneurs had quite considerable existing contacts and networks within their domestic context to help draw upon in order to help grow their current ventures.

The issue of visa requirements was raised with the entrepreneurs. In around half the cohort, visa issues were not seen as something that would be problematic. In one of these instances, one entrepreneur had already secured an H-1B visa. In the other half of the sample, on the other hand, some of the interviewees were deterred from applying for a visa owing to the time it would take. To our knowledge, none of the entrepreneurs had obtained or considered applying for an E-2 visa, which is a temporary visa enabling people to enter and work in the US based on an investment he/she will control while in the US. ${ }^{6}$

\footnotetext{
${ }^{6}$ While none of this small cohort utilised E-2 visas, presumably TEs will be more inclined to seek E-2 type visas if they consider their migratory process to be short-lived.
} 


\section{Findings}

Four central themes emerged from the exploratory interviews (i) the cognitive mindset of TEs (ii) the benefits of the entrepreneurial ecosystem; (iii) perceived benefits of the accelerator and; (iv) links to other entrepreneurial ecosystems.

\subsection{Cognitive Mindset of Transnational Entrepreneurs}

Early on in the interviews, it became clear that the entrepreneurs attracted to the accelerator were highly opportunity-driven, ambitious and growth-oriented, with high levels of entrepreneurial orientation. In addition, they all had a strong external-orientation, which seemed to be a result of their experience and international backgrounds. Nearly all had been educated outside of their home country or had spent time working abroad. Indeed, all bar one of the entrepreneurs had considerable employment experience of working in other countries.

Another sign of the global mindset of these entrepreneurs was the fact that, despite being predominantly non-native English speakers, all spoke perfect English. The vast majority had work experience with other companies prior to becoming entrepreneurs and two of the entrepreneurs had already worked for a period in Silicon Valley. This exposure to the region's entrepreneurial ecosystem seemed to have increased their desire to re-locate their new venture to the region, with entrepreneurs $\mathrm{D}$ and $\mathrm{H}$ noting:

"I love Silicon Valley since it's the global epicentre of innovation and ingenuity; people have dreams here, and they don't quit until they actualize those dreams."

"It's a really inspiring - and contagious - place. People are solving major problems and there is so much to learn and experience and be inspired by."

As noted, the entrepreneurs had work experience outside their own national economies, which had added to their strong external orientation. For example, entrepreneur $\mathrm{G}$ had already worked 
in the Google Tech Hub in London but wanted to relocate to Silicon Valley to create his new venture. This kind of 'global mindset' was emphasised by entrepreneur C:

"I'm building an internationally-focused business where both my employees and customers are likely to be from overseas."

During the course of the interviews it was observed that accelerator programmes in Silicon Valley play a role in (perhaps unintentionally) fostering the entrepreneurial migration process. For example, in two cases the entrepreneurs had no previous connection with, or interest in, Silicon Valley. Chance interactions with some of the region's famous accelerator programmes via their business networks caused them to think about the entrepreneurial ecosystem in Silicon Valley (and micro-ecosystem within particular accelerator environments) and triggered their interest in relocation.

\begin{abstract}
"At the time I applied I had no real connection to Silicon Valley. My only experience was when I was invited to dinner at [name of accelerator withheld]. I saw the huge potential to belong to a group of entrepreneurs because I saw how [name of accelerator withheld] were working together, helping each other".
\end{abstract}

"Everyone knows about the Valley of course, but for me [looking to Silicon Valley] was all about momentum. I knew people there who knew other people there and after talking to them all I thought I'd really benefit from going there."

While the interviewees all had similar ambitions and growth-oriented characteristics, many saw the opportunity to join the accelerator programme as a shared experience. Therefore, the entrepreneurial orientation of these entrepreneurs was partly driven by a desire to work and share ideas with like-minded entrepreneurs who "were also trying to be there and do that". This collegiate or shared endeavour was noted by entrepreneur $\mathrm{H}$, who remarked "I don't think there is a better way to grow." As he explained: 
"It is so important to be able to find like-minded people, technologies, entrepreneurs, start-up funders, and possibly good hires in IT. But also just the environment communitylike-minded people, that's the main rationale."

\subsection{Perceived Benefits of Moving to Silicon Valley}

Given the proliferation of accelerator programmes in Silicon Valley, it seems logical that a key attraction for joining them is the opportunity to benefit from the unique nature of the region's entrepreneurial ecosystem for high-technology entrepreneurs. Indeed, the desire to be close to Silicon Valley for accessibility reasons was a common theme among the entrepreneurs for wishing to join this particular programme. For instance, the entrepreneur A asserted that his main motive for applying to the accelerator was to access the benefits of the wider Silicon Valley ecosystem. He specified that "it's all about proximity and access to resources, funding, and a marketplace."

Entrepreneur D endorsed this view. When asked what sort of locational factors made it attractive to locate in Silicon Valley, he noted factors such as the closeness of potential acquirers, investors, world-class talent and the best mentors in the world.

There is a very good reason why Google, Apple, Facebook and all of our partners are here. There is a great network and we can just talk to them directly when we plan to launch something, do an update or start a massive integrated marketing campaign. This close communication and relationships are essential for our success."

The combination of these factors seemed to augment the richness of the asset pool within Silicon Valley. Having previously lived in Silicon Valley for six months, Entrepreneur D further observed:

"I can accomplish more in a day here, speaking with a handful of people than a week back in Australia. Much more knowledge and mentorship available here." 
In addition to mentoring, recruitment was also an important issue, with a number of entrepreneurs noting the high levels of human capital within Silicon Valley. Most could not specify targets in terms of recruitment, but recognised the potential benefits that undertaking recruitment activities in Silicon Valley could yield.

\begin{abstract}
"It is also about attracting top talent. We want the most talented people in the world to work with us and you can get people in Silicon Valley that you could probably not convince to relocate elsewhere."
\end{abstract}

"We have great people here, but we're always looking for the best and brightest to join the team. And the best and brightest are in Silicon Valley!"

The issue of funding, unsurprisingly, appeared to be an important driver for the entrepreneurs desire to migrate to Silicon Valley. Most of the entrepreneurs had an interest in gaining access to the Valley's well-developed sources of venture capital. As with entrepreneurs A and D, entrepreneurs $\mathrm{C}, \mathrm{E}$ and $\mathrm{H}$ also noted that investments were one of their main motivations for moving to Silicon Valley

\begin{abstract}
"First of all, it's access to resource but also access to venture capital. This is something unique because it's so different in Europe. In California you have a lot of venture capitalmoney that is privately funded, and in Europe there is a mix of public government subsidies or programmes, but it's all not efficient because it's centrally planned, so it doesn't work so well."
\end{abstract}
"Another issue is the availability of capital around the Valley. We never needed to tap into VC money here but it's something we were considering."

\title{
4.3 Perceived Benefits of the Accelerator
}


At the outset, it was expected that applicants would predominantly be interested in gaining funding from the accelerator and the structured mentoring which goes along with the programme. However, to the majority of the applicants the main rationale for joining the accelerator was more to do with the anticipated relational benefits arising from working close by other entrepreneurs on the programme rather than transactional services offered such as funding or structured support. ${ }^{7}$ A core perception was the benefit that start-ups would gain in terms of extending their entrepreneurial networks to other ambitious entrepreneurs and investors.

It was also expected that another key benefit from joining the accelerator would be to access the high-tech cluster of Silicon Valley. However, this was not the primary motivational driver for these TEs. Instead, it was the localized factors or "milieu" associated with the accelerator programme itself that was of greatest appeal for entrepreneurs. Indeed, it became apparent that for most participants the expected social learning and opportunity to develop entrepreneurial networks was perceived to be the main benefit from participation on the programme. This theme was echoed by one of the accelerator's management team:

"After speaking with a lot of companies and a lot of people, we started to realize just how important and powerful the community itself was and how our model is very much geared towards the quality of the interactions, the services, the people, and the various sectors and segments that are going to be supporting the entrepreneurial environment in one way or another."

Comments from the entrepreneurs largely mirrored the remarks made by accelerator's management team. When asked about their motives for applying, entrepreneurs noted that working in close proximity with other entrepreneurs was seen as a critical attraction. Indeed, a

\footnotetext{
7 These perceptions are also strongly apparent from start-ups who have gone through other accelerator programmes, such as Y Combinator. See:www.ycombinator.com/quotes/
} 
core attraction to the accelerator was the importance attributed to peer-based support. The following remarks make specific reference to these localised factors:

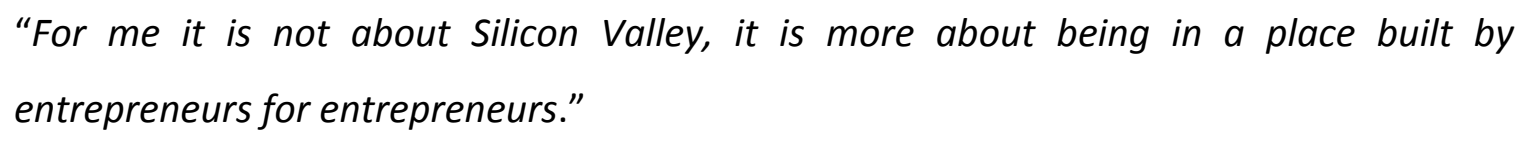
entrepreneurs for entrepreneurs."

"I would say the most appealing parts would be...the opportunity to be utterly and pervasively surrounded by entrepreneurial talent."

"I just want to learn from people who have been there and done it and be with people who have the same energy."

The desire to be co-located with other ambitious and globally-oriented entrepreneurs stood out as a fundamental motivator for the TEs to relocate to the accelerator programme. Again, the entrepreneurs interviewed seemed to place a great deal of emphasis on the shared and mutual benefits they would derive from being closely co-located with other like-minded entrepreneurs. As entrepreneur F claimed:

"Usually entrepreneurs try to help each other and that was one of the other reasons that I saw this option as a good option. We're going to be all together."

Therefore, the interviewees placed great store on the potential benefits that would arise from becoming part of the accelerator's micro-ecosystem. In fact, the "open" and shared nature of the accelerators programme was seen as a vital attraction to the entrepreneurs "to find new ideas" and enact business opportunities. So while the entrepreneurs themselves were confident of their own abilities, the potential for their peers to help hone their businesses emerged as a critical attraction for participating on the programme: 
"Just having the people together may bring tremendous results...may be really exciting and may bring great value."

\subsection{Links to Other Entrepreneurial Ecosystems}

As expected from the nature of TEs, these entrepreneurial migrants had quite varied longer-term intentions in terms of their likely geographical location. Given the cohort and short-term nature of the programme, in the majority of cases the entrepreneur's involvement with the accelerator programme was not seen as a permanent move (and relocation of their business). Indeed, in around half of the cases the entrepreneurs made clear that their involvement in the programme (and in Silicon Valley more generally) was a temporally-bounded process to help grow the business. In many of the cases, the entrepreneurs' viewed either their home environment, or an alternative, as the longer-term location for developing their new ventures.

It appeared from the interviews that the migratory process may in fact be a short-term phenomenon; the vast majority of our entrepreneurs were unable to articulate their expected location post-programme, with the assumption being that they would relocate to the next ecosystem that would best support them and their business needs. For example, Entrepreneur $C$ from Brazil noted that ultimately he aspired to move his company elsewhere in the US, admitting that it is "not just about Silicon Valley" but rather about being in a place with other like-minded entrepreneurs. He noted that his eventual destination was:

"Austin (Texas) because it's an amazing city with good costs and a huge startup community."

Two entrepreneurs were not even willing to commit to full relocation and immersion in Silicon Valley during the acceleration programme, preferring to commute in an attempt to balance involvement in their home ecosystems, as well as within the accelerator's micro-ecosystem. It also seemed the case that personal factors also play a role in their unwillingness to transfer 
permanently to the US. Local investors and other domestic relational connections also seem to shape the behaviour of these transnational entrepreneurs.

"I'll go for a month at a time at the most. I'll need to be back to check on my team as well as my family. But everything will run ok without me for a short time."

"My goal at the beginning was very optimistic I planned to move there [to Silicon Valley], but now I see things differently. I have to authorize a lot of things and I guess the best option is to travel between Mexico and the US. Another reason I changed to this, is because I already have investors from there, I have advisors there - and that's helping me a lot to open doors. So, I just go to Silicon Valley to close some deals and stay there for 2-3 weeks and then I come back. In that way, I can also get back and keep in contact with my family. It wasn't clear to me how much time I was going to need to stay there in the US to raise investments and to start operations."

As well as retaining important connections with their own domestic ecosystem, some of the entrepreneurs highlighted the deterrent factor of having to apply for a work visa to continue their time within the US. Consequently, some of the TEs viewed themselves as "entrepreneurial tourists" who planned to visit the accelerator on an ad hoc basis rather than becoming permanently re-located. According to some entrepreneurs, the issue of work visas was deemed to be a key inhibitor:

\footnotetext{
“Geographical location doesn't matter much for me and some time ago I thought about moving into Silicon Valley, but first of all there were potential difficulties and all these formalities were discouraging."

"Would love to have presence in Silicon Valley, but that will ultimately depend on permits for residency"
} 


\section{Discussion}

This paper makes an important contribution to the burgeoning literature on start-up accelerators and transnational entrepreneurship. It appears that a complex set of motivational and cognitive factors mediate the involvement of TEs within these so-called "start-up factories". That said, the empirical findings presented strongly demonstrate that the critical motivator for wishing to join the accelerator programme was often the strong desire to work intimately with other dynamic entrepreneurial individuals attracted to these flagship accelerator programmes. This corroborates other work showing that the main benefit of accelerators is less about hard forms of transactional support such as finance and training (i.e. "know-how") and more about the enhancement of social capital or “know-who" (Seet et al, 2018).

It appears that these accelerators are also playing an important intermediary or "brokerage mechanism" role, providing start-ups with enhanced relational connections and networks, including with new potential investors. Therefore, the brokerage or intermediation role played by accelerators enables them to engage in crucial "ecosystem intermediation processes" transcending national boundaries (Goswami et al, 2018, p. 147). While much of the literature on TEs emphasises the importance of "strong ties" with like-minded people from the same country or ethnic background, within this cohort the emphasis was very much on the importance of developing new so-called "weak ties" with less well established network actors. ${ }^{8}$ An illustration of these weak relational ties engendered by re-locating to Silicon Valley was the exposure to potential acquirers. This is especially important for many start-ups, many of whom increasingly seek to be acquired rather than to grow into larger scale corporate entities (Livi and Jeannerat, 2015).

The research also enables us to make a contribution to the growing literature on TEs. As previously noted, much of the theoretical literature on TEs hinges on resource dependency. While a number of entrepreneurs talked about accessing resources they could not obtain at

\footnotetext{
${ }^{8}$ Indeed, scholars have noted that an over-reliance on localised embedded ties can derail the performance in some firms (Granovetter, 1973).
} 
home, notably venture capital, it became abundantly clear that the majority did not fit the archetypal "resource dependent" entrepreneur. Rather, these individuals were ambitious and motivated with a strong risk-taking propensity; their motivation to relocate stemmed from a desire to foster stronger relational connections to peers, customers and end-users to help them co-create their firms and products with these other actors. Importantly, every entrepreneur interviewed either came from - or was based in - a major urban entrepreneurial ecosystem, where resources such as venture capital and intellectual property abound. The resources that these entrepreneurs sought were not just the traditional tangible resources such as finance, but rather more "intangible" resources such as access to human capital, tacit knowledge, entrepreneurial "culture" and increased networking opportunities. Therefore, social network theory appears a promising theoretical lens for analysing how TEs overcome and augment their resource limitations. Indeed, scholars note how this theoretical lens can help us better understand "the heterogeneity of agents and the multiplexity of ties that support creation and development of high-tech start-ups" (Ferrary and Granovetter 2009, p. 326).

The complex multi-layered range of networks that these entrepreneurs are embedded within also extends to their home context. Although the TEs were actively seeking to engage with networks within the accelerator and the wider Silicon Valley area, they were still focused on maintaining an embedded presence in their "home" environment, or in ecosystems where they had previously been engaged. For the most part, relocation was considered a temporary phenomenon. This form of "multiple embeddedness" (Liu, 2017, p. 47) is reflective of other work on TEs (Drori et al. 2009) and also chimes with other recent research reporting the importance of multi-polar linkages (Bagwell, 2015). Indeed, the entrepreneurs seemed to confer various benefits from simultaneously interacting within multiple entrepreneurial jurisdictions at any given point in time. It appears that these TEs are quite adept at utilising various locational contexts in order to maximise resources and relational connections to help further their business objectives. 
On the whole, the types of entrepreneurs attracted to these accelerator programmes are differentiated from the bulk of the entrepreneurial migrants that have been examined in the literature on TEs (see Table 2 below). The entrepreneurial ventures in our sample were all located in rapidly growing high-tech markets such as internet-based, software or app based firms. This is in stark contrast to the lifestyle firms typically associated with most TEs (Bagwell, 2015) ${ }^{9}$. Previous literature attempting to classify TEs focuses on their sectoral orientation (Sequeira et al, 2009). While a useful starting point, there are arguably more important cognitive and behavioural factors that mark out different types of TEs such as their risk propensity, previous work-related experiences, motivations for migration and the envisaged nature and permanency of the migration process. Our cohort appears to differ substantially from the archetypal TEs in this respect (see table 2 below). These individuals we label high potential transnational entrepreneurs, have high levels of opportunity recognition, strong levels of international entrepreneurial orientation, low levels of risk aversion and high levels of outward orientation. While admittedly quite a crude dichotomy, this framework allows for some key features to be delineated between these two stylized types of TEs and how new entrepreneurial institutions such as accelerators are shaping their entrepreneurial behaviour.

[Insert Table 2 about here]

\section{Conclusions and Policy Implications}

This paper makes important contributions to both the academic and public policy debates surrounding accelerators. Accelerators are undoubtedly becoming increasingly visible across a large number of entrepreneurial ecosystems. These new entrepreneurial institutions play a central role in shaping entrepreneurial activity and are undoubtedly acting as powerful drivers (and enablers) of transnational entrepreneurship. The paper found that the critical motivator for wishing to join the accelerator programme was the desire by TEs to augment their interaction

\footnotetext{
${ }^{9}$ The bulk of the early literature characterises TEs as resource dependent life-style type entrepreneurs rather than dynamic TEs (Portes et al, 2002). For example, the Vietnamese entrepreneurs examined in one recent study were predominantly service sector start-ups like nail salons, restaurants and takeaways (Bagwell, 2015). We contrast these with the TEs observed in this study in Table 2.
} 
with other dynamic, like-minded entrepreneurs attracted to these types of flagship accelerator programmes. Rather than being driven by a lack of resources, these entrepreneurs are driven by the desire for immersion in the dense myriad of networks and relational connections. While these TEs remain embedded within their home environment to a certain degree, the process of new venture creation seems to be very much a "transnational event" involving multipleembeddedness across various entrepreneurial ecosystems.

This work also has strong relevance for public policy especially given the key role accelerators have been assigned as a mechanism for promoting entrepreneurship (Hochberg, 2016). We can derive from our analysis that attempts to replicate these accelerators within the public sector (or specific geographical locations) may prove problematic, especially within weaker entrepreneurial ecosystems. This chimes with the wider literature on entrepreneurial ecosystems which raises strong concerns about the perils of policy isomorphism (Stam, 2015; Brown and Mason, 2017; Alvedalen and Boschma, 2017).

Evaluation evidence assessing the effectiveness of accelerators is extremely rare and no work has specifically examined how successful they are at attracting non-native entrepreneurs. However, given the unique locational attributes of Silicon Valley, together with the specificities of the accelerator's model examined, this combination seems highly unlikely to be replicable in less advantageous entrepreneurial contexts. While public sector accelerators are now being established in a growing number of European countries, it seems implausible that they will be able to attract the same volume and dynamic types of high-impact TEs attracted to accelerators in Silicon Valley. Publicly-funded hybrid accelerators in particular are highly unlikely to have the magnetic qualities associated with the types of leading-edge accelerators examined.

Furthermore, there could be potential difficulties reproducing the brokerage or "match-making" role accelerators play between start-ups and local equity investors given the limited nature of equity finance in some weaker entrepreneurial ecosystems (Roberts et al, 2018). Plus given their less stringent entry criteria, publicly funded accelerators may also have adverse selection effects 
by attracting low quality start-ups unable to obtain private sector funding elsewhere. Given that the main benefit appears to be the relational connections and mentoring start-ups receive from accelerators, some accelerators may just end up being a source of "dumb" public sector money. ${ }^{10}$ Therefore, similar to the ubiquitous adoption of business incubators by governments and regional development agencies across Europe, which often prove unsuccessful (Tamasy 2007; Brown and Mawson 2016), considerable care should be taken when trying to replicate initiatives in very different contextual environments. This is important because "the nature of the local region, its existing institutions, and its ecosystem" may cause certain types of accelerator programmes "to be more or less effective in a given region" (Hochberg, 2016, p. 48).

Inevitably, the generalisability of these findings are restricted by the small sample examined, as well as the specific nature of the Silicon Valley context. Future studies need to unpack these issues over a wider population of entrepreneurs. It would also be instructive for further examination of accelerators in less dynamic spatial contexts. Additional research could also track the performance of start-ups following their exit from the accelerators to determine the link between acceleration support and firm development and future growth. Given the proliferation of accelerators across the world coupled with their widespread adoption within policy framework, there is a clear and compelling case for much more empirical research on this growing phenomenon.

\footnotetext{
${ }^{10}$ Dumb money contrasts with "smart money" from equity investors owing to the advice and mentoring firms receive from venture capitalists and business angels (Riding, 2008).
} 


\section{References}

Aerts, K., Matthyssens, P., \& Vandenbempt, K. (2007). Critical role and screening practices of European business incubators. Technovation, 27(5), 254-267.

Alvedalen, J., \& Boschma, R. (2017). A critical review of entrepreneurial ecosystems research: towards a future research agenda. European Planning Studies, 25(6), 887-903.

Bagwell, S. (2015). Transnational entrepreneurship amongst Vietnamese businesses in London. Journal of Ethnic and Migration Studies, 41(2), 329-349.

Bergek, A., \& Norrman, C. (2008). Incubator best practice: A framework. Technovation, 28(1-2), 20-28.

Bone, J., Allen, A., and Haley, C. (2017). Business Incubators and Accelerators: The National Picture, BEIS Research Paper 7, Department for Business Energy and Industrial Strategy. https://assets.publishing.service.gov.uk/government/uploads/system/uploads/attachment_dat a/file/608409/business-incubators-accelerators-uk-report.pdf

Brown, R. and S. Mawson. (2016). Targeted support for high growth firms: Theoretical constraints, unintended consequences and future policy challenges, Environment and Planning C: Government and Policy, 34(2): 816-836.

Brown, R., \& Mason, C. (2017). Looking inside the spiky bits: a critical review and conceptualisation of entrepreneurial ecosystems. Small Business Economics, 49(1), 11-30.

Bliemel, M., Flores, R., De Klerk, S., \& Miles, M. P. (2018). Accelerators as start-up infrastructure for entrepreneurial clusters. Entrepreneurship \& Regional Development, 1-17.

Business Finland (2018) Startups, Accelerators and the Role of Tekes, Evalution Report 1/2018, Business Finland. https://www.businessfinland.fi/globalassets/julkaisut/startups accelerators and role of teke s1 2008.pdf

Cassar, G. (2004). The financing of business start-ups. Journal of business venturing, 19(2), 261283.

Chen, W. and J. Tan. (2009) Understanding transnational entrepreneurship through a network lens: Theoretical and methodological considerations, Entrepreneurship Theory and Practice, 33(5): 1079-1091. 
Clayton, P., Feldman, M., \& Lowe, N. (2018). Behind the scenes: Intermediary organizations that facilitate science commercialization through entrepreneurship. Academy of Management Perspectives, 32(1), 104-124.

Dimitratos, P., Buck, T., Fletcher, M., \& Li, N. (2016). The motivation of international entrepreneurship: the case of Chinese transnational entrepreneurs. International Business Review, 25(5), 1103-1113.

Drori, I., B. Honig and M. Wright. (2009) Transnational entrepreneurship: An emergent field of study", Entrepreneurship Theory and Practice, 33(5): 1001-1022.

Dutt, N., Hawn, O., Vidal, E., Chatterji, A., McGahan, A., \& Mitchell, W. (2016). How open system intermediaries address institutional failures: The case of business incubators in emerging-market countries. Academy of Management Journal, 59(3), 818-840.

Easterby-Smith, M., R. Thorpe and A. Lowe. 2002. Management Research: an introduction. London: Sage.

Eisenhardt, K. M. (1989) Building theories from case study research, Academy of Management Review, 14: 532-550.

F6S. (2015) Accelerators. Accessed 15 May 2015. Available at: http://www.f6s.com/accelerators Ferrary, M. and M. Granovetter. (2009). The Role of Venture Capital Firms in Silicon Valley's Complex Innovation Network, Economy and Society, 18: 326-359.

Ganamotse, G. N., Samuelsson, M., Abankwah, R. M., Anthony, T., \& Mphela, T. (2017). The Emerging Properties of Business Accelerators: The Case of Botswana, Namibia and Uganda Global Business Labs. Journal of Entrepreneurship and Innovation in Emerging Economies, 3(1), 16-40.

Gonzalez-Uribe, J., \& Leatherbee, M. (2017). The effects of business accelerators on venture performance: Evidence from Start-Up Chile. The Review of Financial Studies, 31(4), 1566-1603.

Goswami, K., Mitchell, J. R., \& Bhagavatula, S. (2018). Accelerator expertise: Understanding the intermediary role of accelerators in the development of the $B$ angalore entrepreneurial ecosystem. Strategic Entrepreneurship Journal, 12(1), 117-150.

Granovetter, M. S. (1973). The strength of weak ties. American Journal of Sociology, 1360-1380.

Grimaldi, R., and Grandi, A., 2005. Business incubators and new venture creation: an assessment of incubating models. Technovation, 25(2), 111-121. 
Hart, D. M. and Z. J. Acs. 2011. "High-tech immigrant entrepreneurship in the United States", Economic Development Quarterly, 25(2): 116-129.

Hathaway, I. (2016). What startup accelerators really do?. Harvard Business Review, https://hbr.org/2016/03/what-startup-accelerators-really-do

Hochberg, Y. V. (2016). Accelerating entrepreneurs and ecosystems: The seed accelerator model. Innovation Policy and the Economy, 16(1), 25-51.

Howells, J. (2006). Intermediation and the role of intermediaries in innovation. Research Policy, 35(5), 715-728.

Huggins, R., Waite, D., \& Munday, M. (2018). New directions in regional innovation policy: a network model for generating entrepreneurship and economic development. Regional Studies, 52(9), 1294-1304.

Kim, J. H., \& Wagman, L. (2014). Portfolio size and information disclosure: An analysis of startup accelerators. Journal of Corporate Finance, 29, 520-534.

Kohler, T. (2016). Corporate accelerators: Building bridges between corporations and startups. Business Horizons, 59(3), 347-357.

Lamine, W., Mian, S., Fayolle, A., Wright, M., Klofsten, M., \& Etzkowitz, H. (2018). Technology business incubation mechanisms and sustainable regional development. The Journal of Technology Transfer, 43(5), 1121-1141.

Liu, Y. (2017). Born global firms' growth and collaborative entry mode: The role of transnational entrepreneurs. International Marketing Review, 34(1), 46-67.

Livi, C., \& Jeannerat, H. (2015). Born to be sold: Start-ups as products and new territorial life cycles of industrialization. European Planning Studies, 23(10), 1953-1974.

Martin, P. Y., \& Turner, B. A. (1986). Grounded theory and organizational research. The journal of applied behavioral science, 22(2), 141-157.

Miller, P. and K. Bound. (2011) “The Startup Factories", London: National Endowment of Science, Technology and the Arts, (NESTA). Available at: http://www. nesta. org. uk/sites/default/files/the_startup_factories_0.pdf.

Pauwels, C., Clarysse, B., Wright, M., \& Van Hove, J. (2016). Understanding a new generation incubation model: The accelerator. Technovation, 50, 13-24. 
Pfeffer, J. and G. R. Salancik. (2003) Resource dependency theory. In The sociology of organizations edited by M. J. Handel, 233-242. Thousand Oaks, CA: Sage.

Portes, A., L. E. Guarnizo and W. J. Haller. (2002) Transnational entrepreneurs: An alternative form of immigrant economic adaptation, American Sociological Review, 67(2) 278-298.

Pruthi, S., Basu, A., \& Wright, M. (2018). Ethnic ties, motivations, and home country entry strategy of transnational entrepreneurs. Journal of International Entrepreneurship, 1-34.

Riding, A. L. (2008). Business angels and love money investors: segments of the informal market for risk capital. Venture Capital, 10(4), 355-369.

Roberts, P., Davidson, A., Edens, G., and Lall, S. (2018) Accelerating the Flow of Funds into Early Stage Ventures: An Initial Look into Program Differences and Design Choices. Global Accelerator Learning Initiative, The Aspen Institute.

Rodríguez-Pose, A. (2013). Do institutions matter for regional development?", Regional Studies, 47(7): 1034-1047.

Saxenian, A. (2002). Transnational communities and the evolution of global production networks: the cases of Taiwan, China and India. Industry and Innovation, 9(3), 183-202.

Saxenian, A. (2006) The new Argonauts: Regional advantage in a global economy, Cambridge, Mass.: Harvard University Press.

Seet, P. S., Jones, J., Oppelaar, L., \& Corral de Zubielqui, G. (2018). Beyond 'know-what' and 'know-how' to 'know-who': enhancing human capital with social capital in an Australian start-up accelerator. Asia Pacific Business Review, 24(2), 233-260.

Sequeira, J. M., J. C. Carr and A. A. Rasheed. (2009) Transnational entrepreneurship: determinants of firm type and owner attributions of success, Entrepreneurship Theory and Practice, 33(5): 1023-1044.

Shane, S. 2016. Why are business accelerators increasing in number? Small Business Trends. http://smallbiztrends.com/2016/06/business-accelerators-increasing.html

Smith, D. J., and Zhang, M. (2012) Introduction: the evolution of the incubator concept. The International Journal of Entrepreneurship and Innovation, 13(4), 227-234.

Stam, E. (2015). Entrepreneurial ecosystems and regional policy: a sympathetic critique. European Planning Studies, 23(9), 1759-1769. 
Strauss, A. and J. Corbin. 1998. Basics of Qualitative Research: Techniques and procedures for developing grounded theory. Thousand Oaks, CA: Sage.

Tamasy, C. (2007) Rethinking Technology-Oriented Business Incubators: Developing a Robust Policy Instrument for Entrepreneurship, Innovation, and Regional Development?, Growth and Change, 38(3): 460-473.

Terjesen, S. and A. Elam. (2009) Transnational entrepreneurs' venture internationalization strategies: A practice theory approach, Entrepreneurship Theory and Practice, 33(5): 1093-1120. Yeung, H. W-C. (2002) Entrepreneurship in International Business: An Institutional Perspective", Asia Pacific Journal of Management, 19(1): 29-61. 
Table 1. Demographic profile of entrepreneurs

\begin{tabular}{|c|c|c|c|c|c|c|c|c|}
\hline Identifier & Age & iende & $\begin{array}{c}\text { Country of } \\
\text { origin }\end{array}$ & $\begin{array}{l}\text { Nature of } \\
\text { business }\end{array}$ & Education & $\begin{array}{c}\text { International } \\
\text { experience }\end{array}$ & $\begin{array}{c}\text { Entrepreneurial } \\
\text { experience }\end{array}$ & Venture status \\
\hline A & 29 & $\mathrm{M}$ & \begin{tabular}{|c|} 
Dominican \\
Republic
\end{tabular} & $\begin{array}{l}\text { Consumer } \\
\text { goods (3D } \\
\text { printing) }\end{array}$ & $\begin{array}{l}\text { Computer Systems } \\
\text { Engineering; MBA }\end{array}$ & Caribbean; USA & $\begin{array}{c}\text { First venture; } \\
\text { nascent } \\
\text { entrepreneur }\end{array}$ & $\begin{array}{c}\text { Not launched yet; } \\
\text { launch date } \\
\text { undetermined }\end{array}$ \\
\hline B & 27 & $\mathrm{M}$ & Belgium & $\begin{array}{c}\text { Internet/Legal } \\
\text { (small claims } \\
\text { court) }\end{array}$ & $\begin{array}{c}\text { Business/Applied } \\
\text { Economics, Finance \& } \\
\text { Strategy }\end{array}$ & $\begin{array}{l}\text { Santiago, Chile; } \\
\text { Saigon, Vietnam }\end{array}$ & First venture & $\begin{array}{l}\text { Was launched, but } \\
\text { had to close down } \\
\text { the site; will need } \\
\text { to relaunch }\end{array}$ \\
\hline $\mathrm{C}$ & 27 & $\mathrm{M}$ & Brazil & \begin{tabular}{|c|} 
Computer \\
Software \\
$(2 \mathrm{D} / 3 \mathrm{D}$ CAD $)$
\end{tabular} & $\begin{array}{c}\text { Business } \\
\text { Administration and } \\
\text { Management }\end{array}$ & $\begin{array}{l}\text { Austin, Texas; } \\
\text { Canada }\end{array}$ & $\begin{array}{c}5+\text { years of } \\
\text { experience with } \\
\text { the current start- } \\
\text { up (First } \\
\text { venture) }\end{array}$ & $\begin{array}{c}\text { Launched; } \\
\text { released beta test } \\
\text { version in } 2012\end{array}$ \\
\hline $\mathrm{D}$ & 28 & $\mathrm{M}$ & Australia & $\begin{array}{c}\text { Mobile (app } \\
\text { development) }\end{array}$ & $\begin{array}{l}\text { Mechanical } \\
\text { Engineering }\end{array}$ & \begin{tabular}{|c|} 
Silicon Valley, \\
USA; San \\
Francisco, USA
\end{tabular} & $\begin{array}{c}\text { Serial } \\
\text { entrepreneur }\end{array}$ & $\begin{array}{c}\text { Launched; offices } \\
\text { in Melbourne and } \\
\text { San Francisco; } \\
\text { has a decent } \\
\text { amount of IP }\end{array}$ \\
\hline $\mathrm{E}$ & 35 & $\mathrm{M}$ & Poland & \begin{tabular}{|c|} 
Internet (VPN \\
encryption \\
service)
\end{tabular} & $\begin{array}{c}\text { Electronics and } \\
\text { Telecommunication; } \\
\text { Project Management } \\
\text { for ICT Professionals }\end{array}$ & Ireland & $\begin{array}{c}\text { Serial } \\
\text { entrepreneur } \\
\text { (thinking about } \\
\text { starting another } \\
\text { new venture) }\end{array}$ & Launched \\
\hline $\mathrm{F}$ & 38 & $\mathrm{M}$ & Mexico & \begin{tabular}{|c|} 
Internet (talent \\
acquisition \\
platform)
\end{tabular} & $\begin{array}{c}\text { Computer Science and } \\
\text { Business }\end{array}$ & Mexico; USA & $\begin{array}{l}15+\text { years of } \\
\text { experience; } \\
\text { serial } \\
\text { entrepreneur }\end{array}$ & Launched \\
\hline G & 38 & $\mathrm{M}$ & Italy & \begin{tabular}{|c|} 
Cloud \\
computing \\
(PAAS); Music \\
products and \\
services
\end{tabular} & $\begin{array}{c}\text { Literature \& Theatre } \\
\text { with a focus on New } \\
\text { Media; MBA in } \\
\text { Marketing }\end{array}$ & \begin{tabular}{|c} 
Rome, Italy; \\
Tuscany, Italy; \\
Berlin, \\
Germany; \\
Shanghai, \\
China; London, \\
UK; Miami, \\
USA; Los \\
Angeles, USA; \\
Silicon Valley, \\
USA
\end{tabular} & $\begin{array}{l}7 \text { years of } \\
\text { experience; } \\
\text { serial } \\
\text { entrepreneur }\end{array}$ & $\begin{array}{c}\text { Prior business } \\
\text { was established } \\
\text { for } 2.5 \text { years, but } \\
\text { struggled to stay } \\
\text { on the market, so } \\
\text { it closed down in } \\
2013 \text {; now about } \\
\text { to launch a similar } \\
\text { venture }\end{array}$ \\
\hline $\mathrm{H}$ & 30 & $\mathrm{M}$ & India & $\begin{array}{c}\text { Mobile (app } \\
\text { development) }\end{array}$ & Computer Science & UK & \begin{tabular}{|c} 
First venture \\
(other prior \\
experience in \\
family business)
\end{tabular} & Launched \\
\hline
\end{tabular}


Table 2. Delineating Traditional Transnational Entrepreneurs and High Potential Transnational Entrepreneurs

\begin{tabular}{|c|c|c|}
\hline Thematic issues & Traditional Transnational Entrepreneurs & High Potential Transnational Entrepreneurs \\
\hline $\begin{array}{l}\text { Nature of } \\
\text { Entrepreneurs }\end{array}$ & $\begin{array}{l}\text { Low levels of human capital, necessity- } \\
\text { based. }\end{array}$ & $\begin{array}{l}\text { Young, well-educated, high levels of } \\
\text { entrepreneurial orientation. Bi-lingual and } \\
\text { bicultural individuals. }\end{array}$ \\
\hline $\begin{array}{l}\text { Cognitive } \\
\text { Motivations for } \\
\text { migration }\end{array}$ & $\begin{array}{l}\text { Development and maximisation of resource } \\
\text { base (reducing resource dependency within } \\
\text { their home environment) }\end{array}$ & $\begin{array}{l}\text { Access to networks and other forms of social } \\
\text { capital, as well as peer-to-peer experiential } \\
\text { learning; strong focus on personal (and } \\
\text { venture) growth and development }\end{array}$ \\
\hline $\begin{array}{l}\text { Institutional } \\
\text { Drivers of } \\
\text { Transnational } \\
\text { Process }\end{array}$ & $\begin{array}{l}\text { Pushed by a lack of financial resources and } \\
\text { opportunities within domestic economy }\end{array}$ & $\begin{array}{l}\text { Pulled by the desire to join nascent } \\
\text { entrepreneurial institutions such as } \\
\text { accelerator programmes; strong focus to } \\
\text { build relational connection with like-minded } \\
\text { entrepreneurs }\end{array}$ \\
\hline $\begin{array}{l}\text { Sectoral Focus } \\
\text { of Start-Ups }\end{array}$ & $\begin{array}{l}\text { Predominantly (but not exclusively) service } \\
\text { sector, with limited potential for high } \\
\text { economic impact or employment creation }\end{array}$ & $\begin{array}{l}\text { Predominantly high tech sectors, including } \\
\text { software, internet and applications, with high } \\
\text { potential for economic impact and disruptive } \\
\text { technology }\end{array}$ \\
\hline $\begin{array}{l}\text { Geography of } \\
\text { Transnational } \\
\text { Entrepreneurs }\end{array}$ & $\begin{array}{l}\text { Migration predominantly from emerging } \\
\text { market economies or peripheral regions to } \\
\text { developed economies (no particular focus } \\
\text { on key entrepreneurial ecosystems) }\end{array}$ & $\begin{array}{lrrr}\text { Migration from strong } & \text { entrepreneurial } \\
\text { ecosystems to } & \text { other } & \text { international } \\
\text { entrepreneurial ecosystems } & \end{array}$ \\
\hline $\begin{array}{l}\text { Nature of } \\
\text { Relocation } \\
\text { Process }\end{array}$ & $\begin{array}{l}\text { Physical relocation for sustained periods of } \\
\text { time (often permanent with entrepreneurs } \\
\text { sending remittances to dependent family } \\
\text { members) }\end{array}$ & $\begin{array}{l}\text { Temporary/transient. Physical relocation } \\
\text { (impermanent locational factors important) }\end{array}$ \\
\hline
\end{tabular}

